\title{
Retraction Note: Prediction of mountain green vegetation coverage based on wireless sensor network and regional industrial economic convergence
}

\author{
Bize Zhang ${ }^{1} \cdot$ Hong Liang ${ }^{2} \cdot$ Yin Qiong ${ }^{3}$
}

Published online: 25 November 2021

(c) Saudi Society for Geosciences 2021

Retraction Note: Arabian Journal of Geosciences (2021) 14: 1189

https://doi.org/10.1007/s12517-021-07479-4

The Editor-in-Chief and the Publisher have retracted this article because the content of this article is nonsensical. The peer review process was not carried out in accordance with the Publisher's peer review policy. The authors have not responded to correspondence regarding this retraction.

The original article can be found online at https://doi.org/10.1007/ s12517-021-07479-4.

Bize Zhang

Anhui Xinhua Media Co. Ltd., Hefei 230001, Anhui, China

2 Liaoning Jidian Polytechnic, Dandong 118000, Liaoning, China

3 Hefei Wellthink Business Service Co., Ltd., Hefei 230001, Anhui, China 